\title{
MOSTRA ANUAL DE FÍSICA DO RN: Ciência acessível a todos
}

\author{
Jacques Cousteau da Silva Borges
}

Amadeu Albino Junior

Professor do Departamento de Formação de Professores do CEFET-RN

amadeu@cefetrn.br

\section{RESUMO}

No ano de 2003, os professores de Física do CEFET-RN, tiverem a idéia de expor aos seus alunos os equipamentos e experimentos de Física presentes em seus laboratórios. O evento de apenas dois dias foi intitulado "I Mostra de Física do Rio Grande do Norte”, e teve como seu principal público os próprios alunos do CEFET-RN. Nestes dois dias, praticamente todos os servidores e alunos da instituição se deparam com experiências de mecânica, óptica, eletricidade e tantas outras, que despertaram o interesse de muitos alunos, pela ciência e tecnologia. Nos anos seguintes, a mostra cresceu e evoluiu, contanto não apenas com demonstrações de Leis Físicas por experimentos didáticos, mas também com mini-cursos, oficinas, palestras, lançamentos de livros e apresentações de filmes relacionados com a Física e com a ciência como um todo. A partir de uma abordagem lúdica e interativa, alunos e professores do CEFET e de outras instituições vêm participando ano a ano, cada vez mais. O presente trabalho irá tratar de como essa mostra evoluiu nessas quatro edições, além destacar como ela têm incentivado a inclusão de jovens no mundo científico. Por fim, avalia-se a contribuição da Mostra de Física para o curso de Licenciatura em Física do CEFET-RN, analisando a participação e envolvimento dos graduandos nas atividades desenvolvidas nessa "Feira de ciências".

Palavras-chave: Ensino de Física. Mostra de Física. Feira de Ciências. 


\section{MOSTRA ANUAL DE FÍSICA DO RN: Ciência acessível a todos}

\section{INTRODUÇÃO}

A Física é uma ciência de caráter experimental. Logo, não esta sujeita apenas a cálculos, formula e simulações numéricas. Esta sujeita também a pesquisas no campo da investigação experimental. Em relação ao ensino de Física no Nível Médio, os parâmetros Curriculares Nacionais (PCN) propõem um currículo baseado no domínio de competências básicas e que tenham vínculo com as diversas situações do cotidiano dos alunos, buscando dar significado ao conhecimento escolar, mediante a contextualização dos conteúdos trabalhados em sala de aula (ROMANO, 2004).

Diante desta afirmação, é fácil perceber a importância de experimentos em sala de aula. Já que estes trazem o conhecimento de uma forma mais palpável e acessível aos alunos. Um conhecimento Físico, ou seja, científico, de algo que esteja presente no seu cotidiano.

Vale colocar que é proposta pedagógica dos PCN "aplicar as tecnologias associadas às Ciências Naturais na escola, no trabalho e em outros contextos relevantes para sua vida" (MEC, 2000, p 96). E completa Castro: “[...] Assim, enquanto educadores devemos romper com uma diretriz de conteúdo e estanque, trazendo cada vez mais para a sala de aula temas modernos, mais próximos da realidade dos alunos [...]" (CASTRO, CORREIA; GONÇALVES, 2003, p.3).

È pensando nisso que em 2003 surgiu, pela iniciativa do Grupo de Pesquisa em ensino de Física (GEPEF), formado por professores de Física do CEFET-RN, a I mostra de Física do Rio Grande do Norte, também chamada de mostra de Física do CEFET-RN. Esta mostra vem trazer experimentos, palestras, filmes, oficinas e mini-cursos, todos voltados para a prática docente em Física.

A mostra desde então passou a ser um evento anual, com grande participação, de professores e alunos (nível médio, superior e pós) de Física. Este trabalho tem por objetivos descrever em detalhes este evento, mostrando a sua estrutura, e relatando como a mostra de Física tem contribuído para a formação de professores no curso de licenciatura plena em Física do CEFET-RN, como também para a inserção de jovens no mundo científico-acadêmico, além de levar conhecimento cientifico de forma interativa, lúdica e gratuita para todos aqueles que se interessam por ciências.

Na realidade a mostra é uma grande feira de ciências, que como prática pedagógica desempenha um ótimo papel no processo ensino aprendizagem, como detalhado a seguir.

\section{FEIRA DE CIÊNCIAS E PCN'S}

Feira de ciências, conhecidas em algumas escolas como "semana da cultura”, é geralmente caracterizada como um evento que acontece no âmbito escolar, onde as aulas quadro-giz em sala de aula param momentaneamente, para que os conteúdos sejam expostos nos corredores e pátios da escola, fazendo com que toda a escola se torne uma única sala de aula. Repare o que diz NPADC:

as feiras de ciências são alternativas importantes para incentivar e estimular estudantes $e$ professores na busca de novos conhecimentos, oferecendo-se como espaços significativos 
para a iniciação científica (...), [onde os] estudantes se propõem a realizar projetos de investigação científica e os professores buscam formas de atualização de sua prática docente (...) As Feiras de Ciências são, portanto, eventos que fazem a culminância dos trabalhos escolares realizados durante um período letivo. Isto significa dizer que os trabalhos não precisam ser, obrigatoriamente na área de Ciências Físicas e Biológicas. (...) podem ser enfocados $N$ temas, nos seus aspectos sociais, educacionais, metodológicos, etc. (UFPa/NPADC, 1991:7)

Ora, essas feiras são extremamente necessárias, principalmente em escolas que carecem de laboratórios e outros recursos didáticos para o ensino de ciências (Física, Química, Biologia e Matemática). Dessa forma, os alunos se deparam apenas com leis já formuladas, prontas e uma dezena de equações matemáticas, sem ligações com o cotidiano. È como diz GONÇALVEZ: as experiências anteriores da maioria dos indivíduos, em sua vida escolar, foram no sentido de uma ciência puramente descritiva, acadêmica, muito diferente dos princípios que devem nortear o ensino atual de Ciências... (GONÇALVES, 1981:30)

E como deve ser o ensino atual de ciências? Os PCN trazem um currículo baseado em competências. Para a área de Ciências da Natureza e Matemática eles sugerem que o ensino esteja relacionado a três grandes competências: de representação e comunicação; de investigação e compreensão; e de contextualização sociocultural (MEC, 2000).

A partir de agora vamos analisar uma feira de ciências, e observar se o que nela ocorre de alguma forma esta relacionado com o que pedido pelos PCNs, justificando assim a prática desta.

\subsection{Representação e Comunicação}

Qualquer prática pedagógica deve passar por um processo de avaliação contínua, passando por três momentos distintos: a elaboração ou preparação da aula (neste caso a feira de ciências), o momento da execução, e a avaliação do processo, para que na próxima elaboração os eventuais “erros” possam ser corrigidos.

A competência de Representação e Comunicação são desenvolvidas no momento presente ao acontecimento da feira. A comunicação é o processo de transmitir o conhecimento de uma forma acessível e clara para todos. Embora a maior parte das feiras, esse processo de comunicação seja feito de forma oral, é comum encontrar postes, baner, painéis e outras modalidades de apresentações puramente escritas. É interessante para o aluno que ele mesmo apresente, fale, dialogue, sobre o trabalho por ele elaborado.

Lembrando que o professor não é um elemento inerte nesse momento, cabe a ele orientar os alunos, observar as explicações e avaliar se o que esta sendo falado esta coerente com o experimento, e até mesmo substituir parcialmente o seu aluno - orientando nas apresentações em alguns casos especiais.

A representação, na maioria das vezes, é o momento em que se que chegar. Representar de forma simples algo presente nos livros, é o objetivo da maioria dos trabalhos em uma feira de ciências. Este processo é fundamental para quem elabora o trabalho como também para aqueles que virão prestigiá-lo.Para ilustrar isso observe a figura 01: 


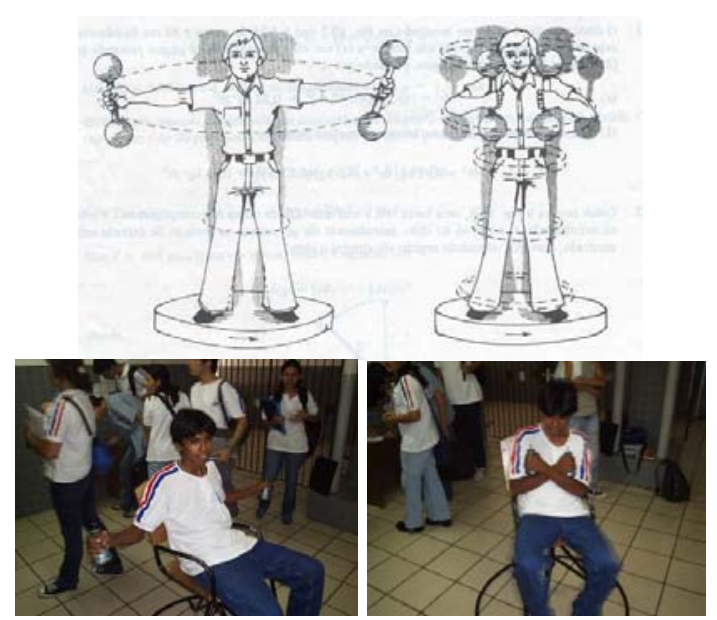

Figura 1 - Conservação do momento angular: visto pelos livros e visto pela mostra

Temos aqui uma imagem presente em livros de Física, sob a conservação do momento angular, ao se abrir e fechar os braços. Modificando a distribuição de massa (momento de inércia), modifica-se a velocidade angular, embora o momento angular total não se modifique. Logo baixo temos uma figura de um aluno sentindo a variação da velocidade angular. Não é possível a todos os alunos girar no experimento, mas é possível a todos ver, observarem a variação. Uma cobaia já é o suficiente! Esse mesmo conceito (conservação do momento angular) pode ser representado por algo mais simples. Basta que gire e que possamos modificar a distribuição da massa.

E nessa representação que os fenômenos podem ser observados e melhor entendidos, já que temos alguns fenômenos físicos, que a primeira vista fogem do senso comum, ou que não estão presentes no cotidiano da maioria dos alunos.

\subsection{Investigação e compreensão}

As competências da investigação e compreensão sugeridas pelos PCNs, se dão na etapa de elaboração dos trabalhos. Tudo começa com uma idéia, geralmente sugerida pelo professor. A partir daí os alunos se reúnem, dividem tarefas, estipulam datas e metas, para que quando chegue à feira de ciências, esteja tudo pronto para ser apresentado.

Em meio a esse processo, os alunos se tornam cientistas, pois passam a pesquisar o tema proposto, a desenvolver protótipos, maquetes, experimentos ou qualquer outro modelo que possa ajudar a explicar determinados conceitos. O enfoque deve ser dado nas coisas do dia a dia dos alunos.

Neste processo, a investigação é uma competência a ser desenvolvida naturalmente, embora a compreensão precise, por muitas vezes, ajuda do professor, para esclarecer alguns conceitos ou organizar melhor algumas idéias pesquisadas pelos alunos.

Em alguns casos, esse pode ser um processo longo, por isso a feira deve ter uma data, e ser divulgada com bastante antecedência, para que os alunos tenham tempo de desenvolver as suas idéias e fazerem as suas pesquisas.

\subsection{Contextualização sociocultural}


Esta ultima terceira grande competência a ser desenvolvida no ensino das ciências, precisa de um incentivo por parte da organização. O nosso país é um lugar de muitas culturas, e infelizmente, de muitos problemas de ordem social. Por isso, um tema livre não seria interessante para os alunos. Geralmente as feiras de ciências possuem um tema Geral, relacionado com algo atual. E os alunos, devem de alguma forma relacionar os seus trabalhos a este tema. Um exemplo disso e que os dias atuais, o que mais se vê são feiras sob o tema "aquecimento Global". Dessa forma leva os jovens não apenas ao conhecimento cientifico, mas também a responsabilidade Social a respeito do Tema.

Uma grande contribuição Sociocultural que é dada nas feiras reside no fato delas serem eventos abertos, divulgando então os trabalhos para toda a sociedade. E fato que os moradores da região onde se encontram a escola procurem visitá-la nessa época de divulgação.

\subsection{Mostra Anual de Física do RN}

É nesse contexto de Feira de ciências que surge a mostra anual de Física do Rio Grande do Norte, Organizada pelos professores de Física do CEFET-RN, através do GEPEF. A mostra atende a todas as características descritas anteriormente, trabalhando assim as competências sugeridas pelos Parâmetros Nacionais, não apenas para o ensino médio, mas também para o ensino Superior, já que o CEFET-RN conta um curso de Licenciatura Plena em Física. Desse modo, a mostra se torna um instrumento de extrema importância na formação de nossos professores de Física. Que em sua grande maioria levam os conceitos aqui mostrados e vivenciados na mostra de Física para as suas futuras salas de aula.

Dessa forma, a mostra de Física do CEFET-RN, vem reincorporar esse espírito científico, divulgando os trabalhos desenvolvidos em seus laboratórios "em um momento de forte interação com a comunidade, cumprindo um compromisso de disseminação do conhecimento científico para essa comunidade” (GONÇALVES \& NEVES, 1987).

De agora em diante, este trabalho objetiva descrever em detalhes a Mostra de Física do CEFET-RN, desde os meios para a sua organização como os resultados alcançados com ele. Esperemos que aqui, professores e alunos possam encontrar incentivo e boas idéias para que esta idéia esteja presente em cada escola da Rede e de nosso país.

\section{METODOLOGIA}

A mostra de Física é um evento anual de apenas três dias, mas como qualquer grande encontro, é necessário uma preparação prévia, com alguns messes de antecedência.

A sua organização fica sob a responsabilidade de um coordenador, que será responsável em incentivar as reuniões do quadro de professores de Física (e de outras disciplinas, quando necessário) para que assim todos possam dar as suas contribuições. São nesses momentos que são definidos os temas para eventuais palestras, mini-cursos, oficinas e/ou exposições de vídeos. Também se define, em parte, os responsáveis por essas atividades, ou seja, os professores que irão ministrar as palestras/mini-cursos, dentro outros.

Lembramos que a mostra de Física não é simplesmente uma feira de ciências do CEFETRN, mas sim um evento de caráter Estadual, o que pede a participação de outras entidades, tais a Universidade Federal do Rio Grande do Norte (UFRN), a Universidade Estadual do 
Rio Grande do Norte (UERN), a Secretaria Estadual de Educação (SEEC) e, as outras unidades do CEFET-RN, como se observa abaixo:

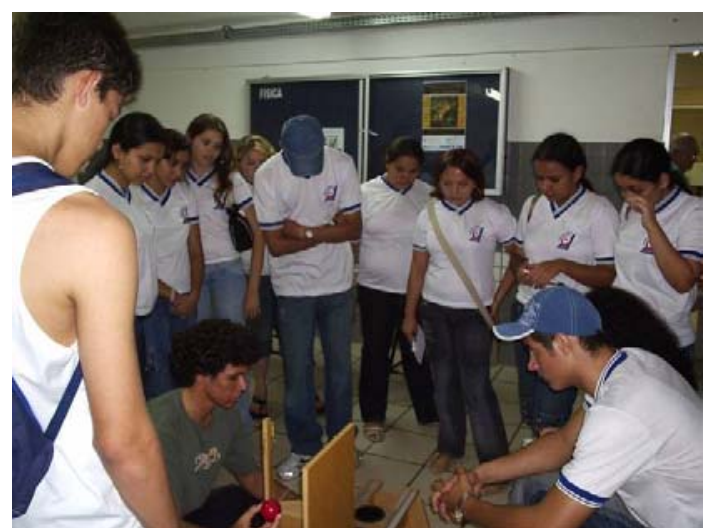

Figura 2: Alunos da UNEDE - Currais Novos, participando da mostra de Física (2006)

Aos Docentes dessas (como também de outras) instituições de ensino são feitos convides, para atuarem como palestrantes de algum tema, ou participarem de mesas redondas, onde ocorrem debates relativos a prática dos docentes de Física na atualidade.

Paralela a programação acadêmica descrita acima, há a exposição de experimentos interativos. A maior parte deles é do próprio laboratório de Física, mas há também uma grande parte de material desenvolvido pelos alunos do nível médio-integrado, como também trabalhos desenvolvidos por alunos da Licenciatura em Física, em disciplinas como as Físicas experimentais ou Instrumentação para o ensino de Física.

A apresentação dos trabalhos e dada de forma voluntária por seus desenvolvedores, por alunos-monitores, por alunos da licenciatura em Física, bem como pelos professores do CEFET-RN, como se pode ver na figura a seguir:
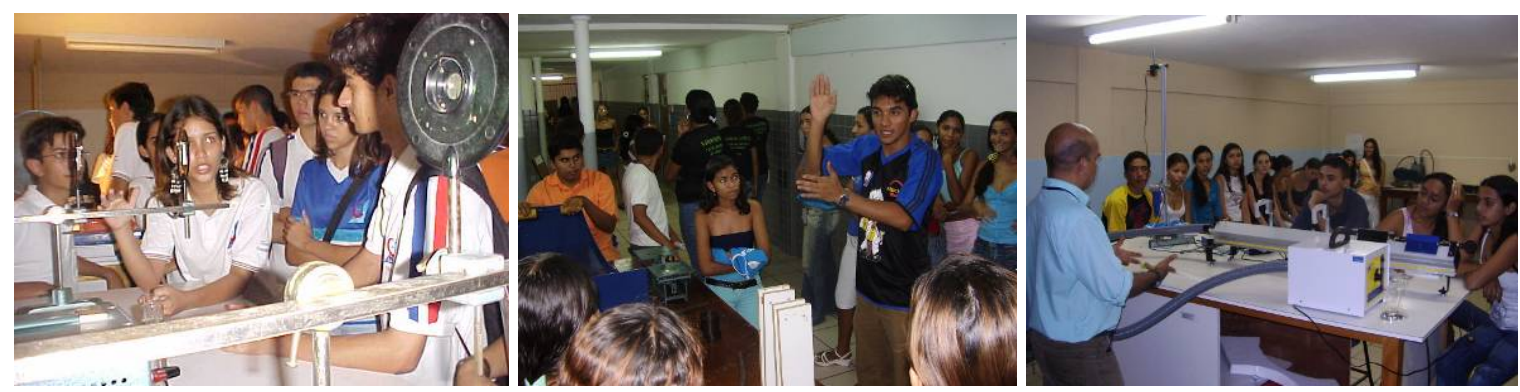

Ilustração 3: Apresentação de Experimentos por Alunos Nível Técnico-integrado, Superior (Licenciatura em Física ) e Professores (2005)

Um ponto importante é a divulgação. Não há como haver público, se o público nem mesmo sabe o que esta ocorrendo. A divulgação se da por meio de cartazes, espelhados pelas escolas da cidade e pelos CEFETs do Estado. O meio eletrônico (internet) também é utilizado, onde os visitantes da pagina principal da instituição (www.cefet-rn.br) podem ver fotos das mostras anteriores, e a sua data e programação (nas proximidades do evento). Uma grande contribuição é a divulgação por meio de comunicação em massa, como a TV e 
o rádio, que na maioria das vezes não impõem dificuldades para a realização da matéria (figura 4):

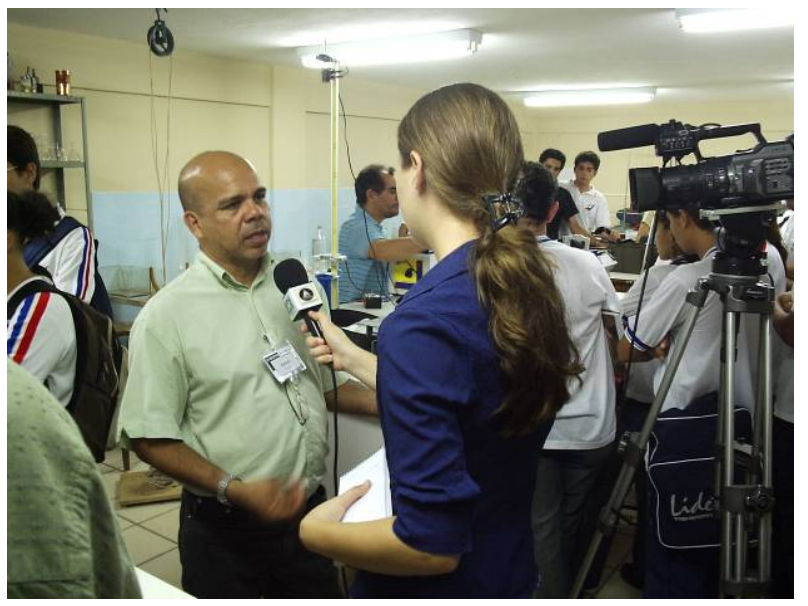

Figura 4: Divulgação em TV aberta local (2006)

Após todos os preparativos, a Mostra de Física do Rio Grande do Norte esta pronta para começar. Durante o período do evento, os alunos são dispensados das aulas de Física, para poderem participar ativamente da mostra. Vale lembrar que a participação não se da apenas pelos alunos do CEFET-RN, mas também por diversas escolas tanto Públicas como Privadas.

\section{RESULTADOS}

O que começou como uma iniciativa simples, atingiu proporções inesperadas. A mostra de Física já esta fazendo parte do calendário de diversas escolas da cidade do Natal.

Dessa forma, ela cumpri o seu papel, divulgando conhecimento científico de forma simples, acessível e direcionada ao cotidiano de seus freqüentadores, desmistificando a idéia de que a Física é uma disciplina difícil e complicada, entendida por poucos.

A mostra também é um espaço onde os alunos da Licenciatura em Física do CEFET-RN podem apresentar os seus trabalhos experimentais desenvolvidos nas disciplinas. Esse fato incentiva os graduandos, fazendo com que eles se dediquem mais as atividades do curso, elaborando materiais didáticos de melhor qualidade (prática e didática). Além de proporcionar aos futuros professores um contato direto com um público típico da profissão (alunos de nível médio).

Foi notado que durante o período da Mostra, temos diversos alunos em pleno estagio curricular obrigatório. Esses alunos da licenciatura trazem os seus "alunos" para participarem, interagindo com os experimentos e ouvindo explicações. Como os graduandos realizam o seu estagio em escolas de rede pública estadual de educação, que em sua maioria carece de docentes de física em seu quadro permanente de professores, esta "aula passeio" acaba se tornando o único contato experimental que esses alunos têm durante a sua passagem pelo ensino médio. 


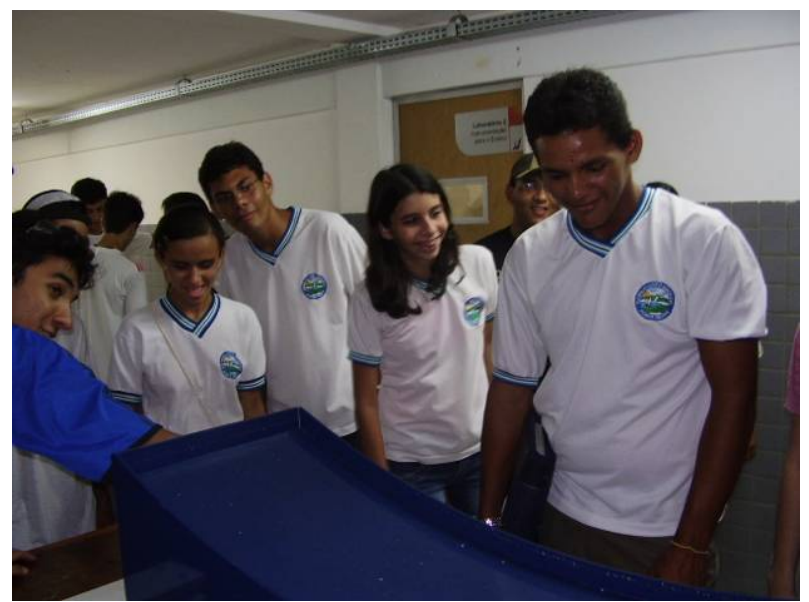

Figura 5: Alunos da Rede Pública (E. E. José Fernades Machado) Interagindo com Experimento

\subsection{Interdisciplinaridade}

A ação dos professores de Física incentivou a participação de outros docentes do CEFET$\mathrm{RN}$ a participarem da mostra, promovendo assim atividades interdisciplinares, tais como experimentos ou demonstrações onde outras disciplinas (como a matemática, a química e a Biologia) podem dialogar conhecimentos com a Física. Dessa forma alunos que não se dão bem em Física, e possuem certo "pavor" dessa disciplina se aproximam do evento a partir da relação de outras disciplinas. Podemos citar como exemplos de atividades desenvolvidas de forma interdisciplinar a construção de pilhas e Baterias e/ou eletrólises (Física - Química), e dissecação de um olho de Boi para mostrar seus componentes Físicos (Física - Biologia), Tais como cristalino, retina, etc.

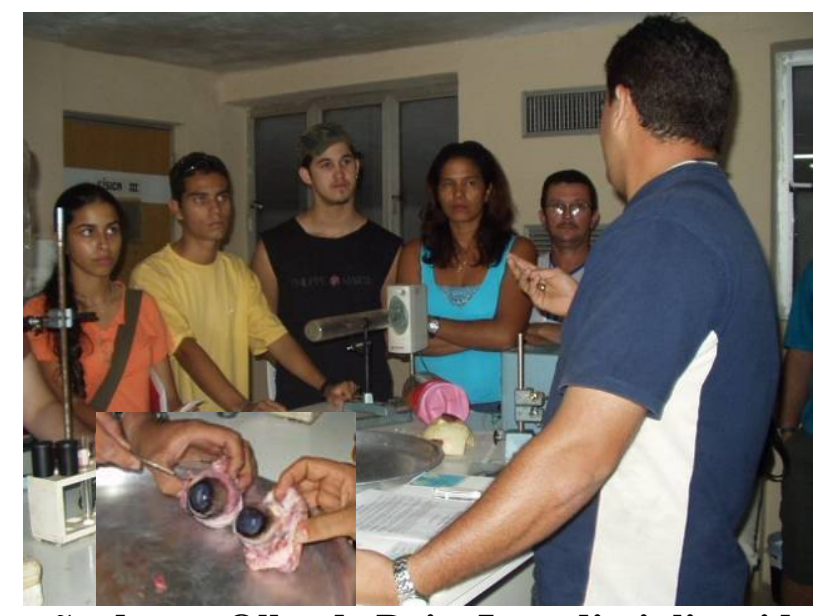

Figura 6: Dissecação de um Olho de Boi - Interdisciplinaridade Física-Biolgia 


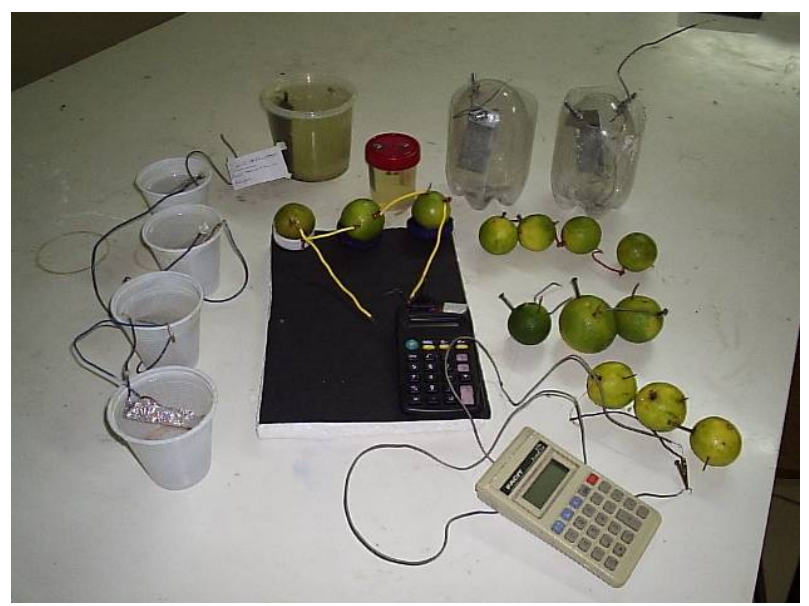

Figura 7: Funcionamento de Calculadora a partir de Pilhas de Limão Interdisciplinaridade Física-Química

\subsection{Jovens cientistas}

Mas, sem sombra de duvida, o resultado mais significativo alcançado com a ostra de Física, é o desperta na juventude o espírito cientifica, o olhar empírico sobre a natureza. Não são poucos os relatos de jovens que após passarem pela mostra anual de Física do Rio Grande do Norte, optaram em seguir o caminho da pesquisa e da investigação, bem como o da experimentação, construindo experimentos apenas por diversão. È uma forma bastante Lúdica de aprender os conceitos e leis envolvidas em cada montagem.

A figura 8 mostra o um gerador de Van de graff do laboratório de Física, e a partir da orientação dos professores, têm-se ao lado "mini geradores” desenvolvidos pelos próprios alunos a partir de uma atividade sugerida. Ao verem o gerador original e perceberam que também podiam fazer um, os alunos se dedicaram e empenharam-se até obterem o melhor resultado possível, passando assim por todas as etapas que envolvem a construção de um experimento. Desde a idéia, a construção, a avaliação dos erros, substituição de materiais, ajustes, dentre outros. O resultado foram geradores que funcionavam tão bem quanto o primeiro, e este ilustravam a mostra com seu funcionamento simples.

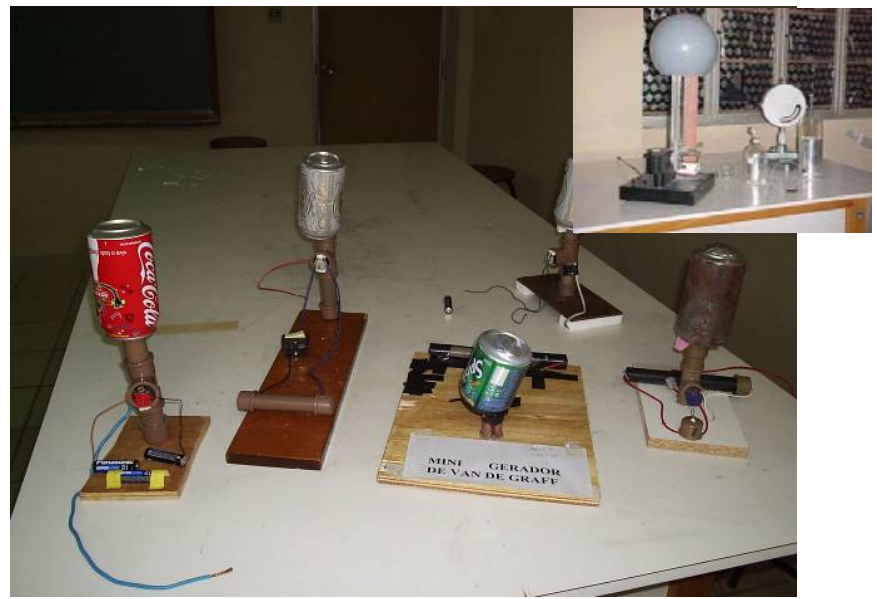

Figura 8: Mini geradores de Van de Graff 
Tal fato mostra que não é impossível ter a mão experimentos simples e de baixo custo, e este é apenas um exemplo entre tantos.

\section{CONCLUSÕES}

Por fim, a mostra de Física do RN só tem a contribuir, não apenas para o CEFET-RN, mas para toda a comunidade, já que vem trazer conhecimento de forma acessível, lúdica e interativa. A retribuição da sociedade é observada com suas visitas, não apenas no período do evento, mas também ao longo do ano, onde alunos e professores frequentemente procuram a equipe da Mostra de Física para tirar duvidas, ou pedir sugestões para criar suas próprias mostras escolares (feira de ciências). Aos poucos, o CEFET-RN esta se tornando uma referência em atividades experimentais didáticas para o ensino de Física.

Uma prova disso foi a mostra do ano de 2005, ocorrida durante uma enorme greve dos servidores federais da educação. Nesse ano, durante os três dias da mostra, os corredores do laboratório de Física permaneceram cheios, mesmo com todo o resto do CEFET-RN fechado devido a greve.

\section{REFERÊNCIAS}

CASTRO, Ronaldo A. de; CORREIA Filho, João A.; GONÇALVES, Heitor A., A inserção da física moderna no ensino médio, in: XV Simpósio Nacional do Ensino de Física, p 1780 - 1789, 2003.

GONÇALVES, T. V. O. e NEVES, S. R. G. Feiras de Ciências. São Paulo: Revista do Ensino de Ciências, nº 24, 1987.

GONÇALVES, T. V. O. METODOLOGIA DA CONVERGÊNCIA: Indivíduo, Conhecimento e Realidade - uma proposta para formação de professores de Ciências. São Paulo: UNICAMP, 1981. 234 p. (Dissertação, Mestrado. Metodologia do Ensino)

MEC, Bases Legais dos PCN - Ensino Médio, Ministério da educação, 2002. Disponível em <http://portal.mec.gov.br/seb/arquivos/pdf/baseslegais.pdf $>$ acessado em 16 de dezembro de 2006.

ROMANO, Jair Carlos. Governo do Estado do Rio Grande do Norte: Ensino Médio de qualidade. Física. Natal: Sistema de Ensino Holos, 2004.

UFPa/NPADC. Projeto: Feiras Regionais e Estaduais de Ciências: uma proposta para interiorização da melhoria do Ensino de Ciências e Matemática no Estado do Pará. Documento interno. Belém/Pa: 1987.

ALBINO JUNIOR, Amadeu, BORGES, Jacques Cousteau da Silva. MOSTRA DE FÍSICA EXPERIMENTAL - UM RECURSO DIDÁTICO PEDAGOGICO. XXV Encontro de Físicos do Norte e Nordeste. Natal-RN, 2007 